\title{
Tulsa's Art Deco Cross-Platform Mobile Tour App
}

\author{
Cameron Beckfield \\ Tandy School of Computer Sciences \\ 800 S. Tucker Drive, \\ Tulsa, OK 74104 \\ cameron-beckfield@utulsa.edu
}

\author{
J C Diaz \\ Tandy School of Computer Sciences \\ 800 S. Tucker Drive, \\ Tulsa, OK 74104 \\ diaz@utulsa.edu
}

\section{INTRODUCTION}

This paper outlines the generation of cross-platform mobile virtual tour apps for Art Deco buildings in Tulsa, Oklahoma. Tulsa was a very young city that was experiencing unprecedented growth and prosperity fuelled by oil money in the Roaring Twenties. At the same time the Art Deco movement was becoming fashionable. Prominent Tulsans build the skyscrapers that stimulated one of the preeminent Art Deco collections in the United States.

\section{ART DECO STYLE}

The architectural style known as Art Deco first appeared after World War I in France. It flourished until the onset of World War II. Art Deco was an eclectic style. It combined the traditional, crafts and motifs, with the modernistic, machine age imagery and materials. The style salient characteristics are the lavish ornamentation, bold geometric shapes, and rich colours. In the late 1920s, Tulsa was known as 'Terra Cotta City' because of its Art Deco buildings.

\subsection{Art deco styles in Tulsa}

There are three main styles of Art Deco. The Zigzag style appeared in the 1920s because it made height appear more prominent and was widely used in skyscrapers. The Public Works Administration (PWA) provided for construction jobs for public buildings. The PWA style ended with the end of the great depression when the Art Moderne or Streamline style came into vogue.

Tulsa has great examples of all these three styles. The Mobil App Tour includes buildings selected as representatives from each style. Eleven buildings represent the Zigzag style. Two represent the PWA style. And eight represent the Streamline style.

\section{TULSA ART DECO MOBILE TOUR}

Mobile devices and corresponding apps have become part of people's lives. There are many mobile platforms in the ecosystems (Android, iOS, Windows), size variations (phones, tablets), and version differences of the operating systems. In order to reach the maximum number of devices possible, it is becomes necessary to create a separate version of each app for each one of mobile devices. A significant barrier that requires large amount of effort porting the app and mastering the code for each system as well as managing future updates. Two applications help to get around this problem: PhoneJS and PhoneGap.

PhoneJS allows for the creation of one single web app that will automatically be adjusted to be properly viewed on the user's device whatever it is. The app is created with the PhoneJS framework based upon HTML, JavaScript, and CSS. Once built, it can be compiled as a native phone app with the use of PhoneGap. This allows for one code base that can be easily learned, managed, implemented and supported.

\section{REFERENCES}

List of Art Deco buildings in Tulsa, Oklahoma. https://en.wikipedia.org/wiki/List_of_Art_Deco_build ings_in_Tulsa,_Oklahoma (retrieved 18 March 2014).

PhoneGap. http://phonegap.com/ (retrieved 18 March 2014).

PhoneJS. http://phonejs.devexpress.com/ (retrieved 18 March 2014).

Tulsa's Art Deco Heritage. http://www.tulsapreservationcommission.org/artdec o/ (retrieved 18 March 2014). 


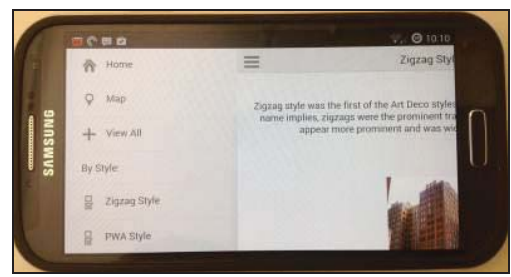

Figure 1: Android Version of the App

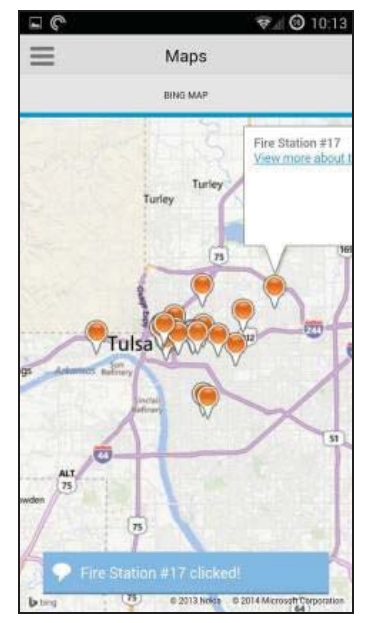

Figure 2: Android Screenshot of Tour map

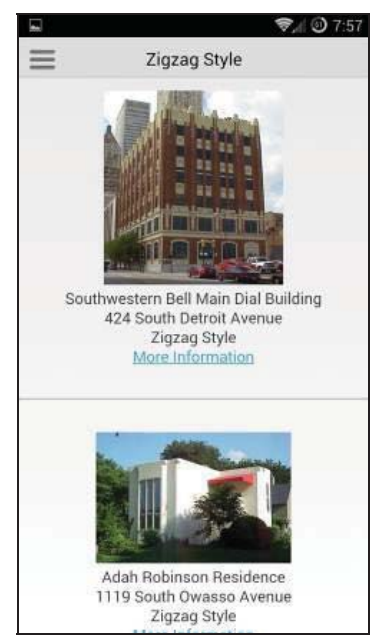

Figure 3: Android Screenshot of Zigzag Style

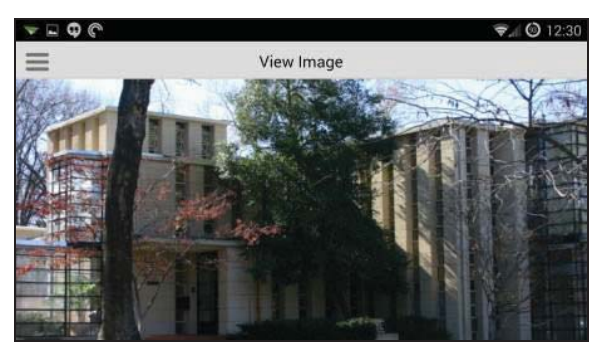

Figure 4: Westhope designed by Frank Lloyd Wright, 1929 - Android App

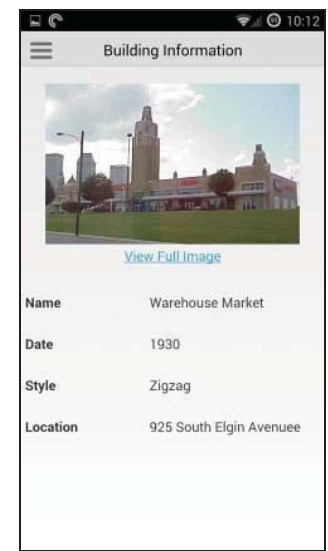

Figure 5: Building information - Android App

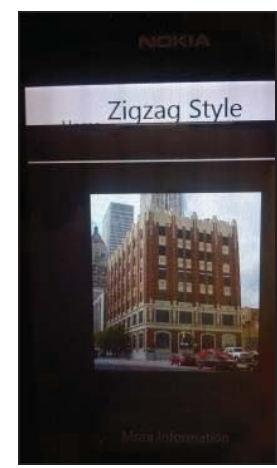

Figure 6: Zigzag Style - Nokia Web App

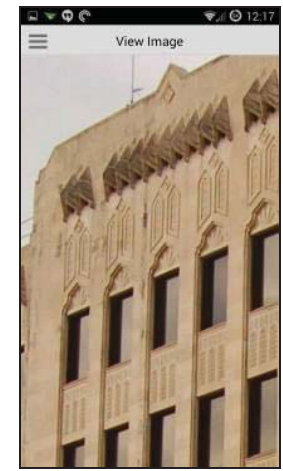

Figure 7: Zigzag Style Detail - Android App

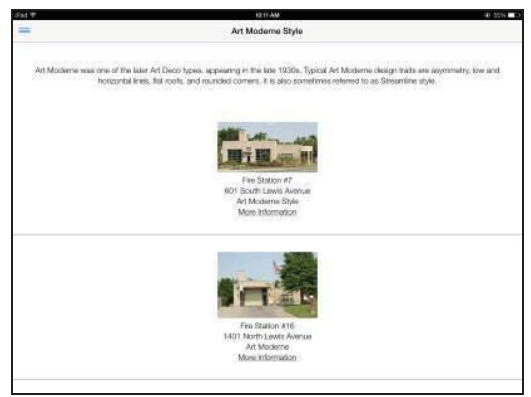

Figure 8: Art Moderne - iPad App 